\title{
Application of Maize Precision Fertilizer Expert System in the Maize Production
}

\author{
Yao Yuxia, Zhang Yun \\ The Information Engineering College of Changchun University of Science and Technology, Ji Lin \\ Chang Chun 130600 China \\ yx--yao@163.com; 250814909@qq.com;
}

Keywords: expert system, maize production, precision agriculture, information technology

\begin{abstract}
According to the nowadays production conditions of JinLin province, The effective system was developed by utilizing the knowledge of agricultural production, computer science and internet technology and so on in the paper. In order to reach the aim, the author combined theory model and quantitative research and developed the system. It will inject a kind of new action and energy into maize fertilizer research. There were four innovations in the system like the followings. Author established knowledge base and complex database by summing up some information of maize precision fertilizer. Lower fertilizer invest and environment pollute.
\end{abstract}

\section{Introduction}

Agricultural expert system is also called agricultural intelligent system, it is the use of artificial intelligence expert system technology, combined with the characteristics of agriculture developed a high-tech. Agricultural expert system using artificial intelligence, knowledge representation, reasoning, knowledge acquisition technology, summarized and pooled a lot of valuable experience accumulated agricultural experts as well as various information and data obtained through experiments and mathematical models of such knowledge, and the development of computer software systems ${ }^{[1]}$.

Agricultural expert system can not only save, spread all kinds of agricultural information and agricultural knowledge, but also be able to decentralized, local, individual agricultural technologies organically integrated, through intelligent information processing, for different production conditions, to various problems given systematic and highly strain solutions for the agricultural production of the entire process or precise production processes provide a level of service experts, thus promoting the development of agricultural production ${ }^{[2]}$. Currently, the group has developed a "corn precision fertilization expert system", "multimedia corn pests diagnosis expert system", "special maize production expert systems," "corn yield standardized cultivation system", "corn deep processing technical advisory system" and "corn breeding management system" and other six sub-systems, maize production in Jilin played an important role in guiding.

\section{The main function of maize precision fertilizer expert system}

Corn precision fertilization expert system is the application of knowledge-based rules, said the use of inference engine technology, object-oriented programming, database, multimedia and other technologies, the use of $\mathrm{VC}++6.0$ visualization software development tools developed from. System including the main content of the basic aspects of maize production forecast by the production, selection of species, yielding fertilization, soil nutrient balance fertilization, fertilizer effect function of fertilization, benefit analysis, statistics, and system maintenance eight functional modules. GIS system and combined with fertilizer as a breakthrough, combined with production forecast, according to the corresponding block name and soil nutrients measured values entered by the user, production efficiency, low input high output ${ }^{[3]}$. This system can really be applied to actual production, experts and agricultural extension workers provide technical guidance to farmers, saving manpower and material resources. 
The system interface is simple, strong fault tolerance. The main interface of the most popular Windows window basic form consists of five parts, the top title bar, indicate the name of the software, took the menu bar, the menu can be done through a variety of operations, is below the menu tool bar, you can quick and easy to complete common basic operations, the middle part is the biggest user window, the bottom is the status bar for the user's operation to provide basic tips. Corn precision fertilization expert system block diagram of GIS support (Figure 1).

\section{The system of application of technology, knowledge representation and reasoning mechanism}

Use of this system can be divided into three cases: in conjunction with GIS users independent consultant, the database farmers information centrally, and statistical data ${ }^{[4]}$. When a user in accordance with the "User Registration (login), production forecasts, species selection, rational fertilization, benefit analysis, display results, statistics, print" in order to use the software. For the above three cases will be described with the use of the software.

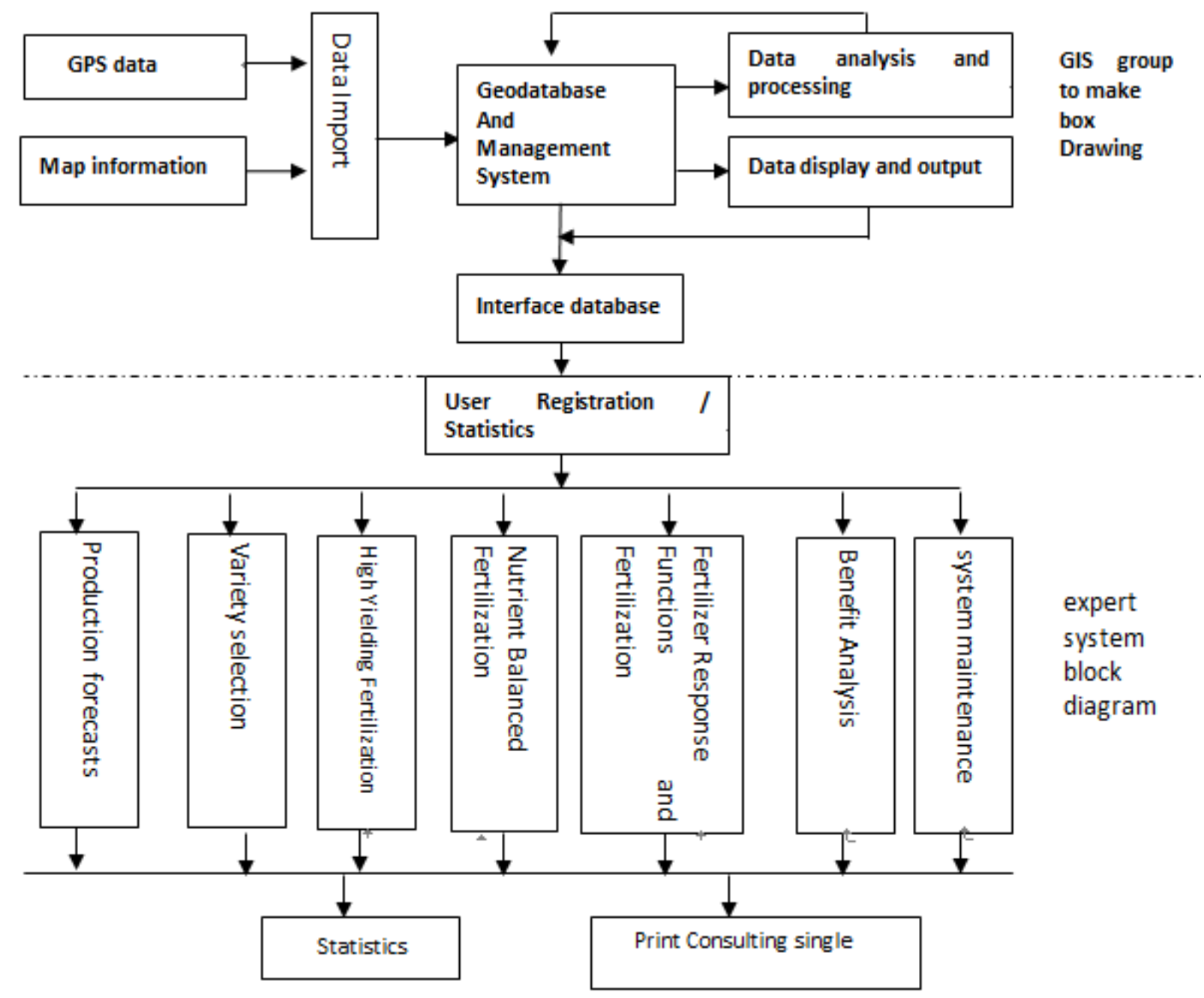

Fig.1 Frame diagram of the corn precision applies fertilizer the expert system

\section{With GIS (geographic information system) and the use}

Start the GIS (geographic information system), on the electronic map to pinpoint the farmers and the farmers to export information. Then run the "corn precision fertilization expert system", the relevant soil data series farmers calculated reasoning, and ultimately give fertilizer recommendations, and print a single consultation. As "User Registration (login)" Module Description 
After entering the main interface, you can start in one of two ways, "login" screen: Click on the toolbar shortcut icon (Figure 2). By choosing the menu bar "User Registration" drop-down menu and click "Run" landing (Figure 3)

After startup, select "GIS", "User Registration (login)" screen will automatically display the farmers exported from the GIS basic information (Figure 4), click on the "Import data", will pop up the "new user" prompt box, indicating that the information has been registered farmers (Figure 5) in the database, then "return" to exit.

\section{"Rational fertilization" module description}

Ibid landing "rational fertilization" interface in two ways. In this module, through the "high-yield fertilizer", "soil testing, fertilizer" and "fertilizer effect function method" measured three ways of reasoning fertilizer. Such as the use of "high-yield fertilizer" method, select "High Yielding Fertilization" option. Fill in the correct acreage, select the type of fertilizer. If the annual application of organic manure, then select the check box, and then select the application rate according to the actual situation, and finally click on "Advisory" to see the use of "high-yield fertilizer" fertilizer fertilization methods. Advice. "Print" corn fertilization Advisory List "view displays advisory single result, after confirmation, click on the toolbar" Print "shortcut icon to start the printer will print out the results of the consultation, in order to prepare for future use and reference.

\section{Uses a rule-based knowledge representation}

In the "corn precision fertilization expert system", using a rule-based knowledge representation, rule-based expert system, the knowledge of the use of production represented ${ }^{[5]}$ :

If (Premise 1) \& (premise 2) \& ....... then (Conclusion 1) where part of the former member if clause, then clause is part of the back piece.

Corn precision fertilization system, we will yield prediction rule to production in the form of storage in the Knowledge Base, for example:

Rule: If Lot 5 to September annual rainfall greater than $400 \mathrm{~mm}$, the land accessibility factor production: IF $\mathrm{J}=2$ THEN $\mathrm{Z}=0$

Wherein $\mathrm{J}$ represents Lot 5 to September annual rainfall of less than $350 \mathrm{~mm} 0$ represents, it represents less than $400 \mathrm{~mm}$ and not less than $350 \mathrm{~mm}$, two representatives of more than $400 \mathrm{~mm}$. Similarly, Z represents the Obstacles to Lot, 0 for none, 1 representatives.

Production forecasts of part of the rule as follows:

The same three-year average yield of other farmers fertility $=$ (equal fertility + other farmers in the previous annual fertility before other farmers two equal annual + three equal annual fertility other farmers) / 3

IF Lot 5 to September annual rainfall of less than $350 \mathrm{~mm}$ of soil structure $V$ sand, clay, waterlogged lowland, upland and easy sand erosion, saline, barren slope of cultivated land, THEN there are the Obstacles to Lot

IF Lot 5 to September annual rainfall of less than $400 \mathrm{~mm}$ and not less than $350 \mathrm{~mm}$ of rainfall unevenly distributed $\wedge$ THEN Lot obstacles Factors

IF Lot 5 to September annual rainfall of less than $400 \mathrm{~mm}$ and not less than $350 \mathrm{~mm}$ of rainfall distribution $\wedge$ THEN Lot accessibility factor

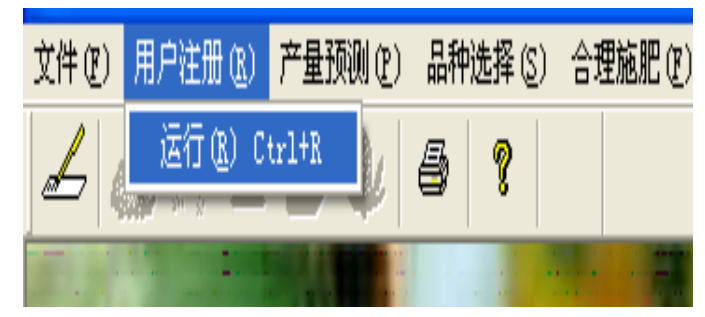

Fig.2 Circulate the debarkation

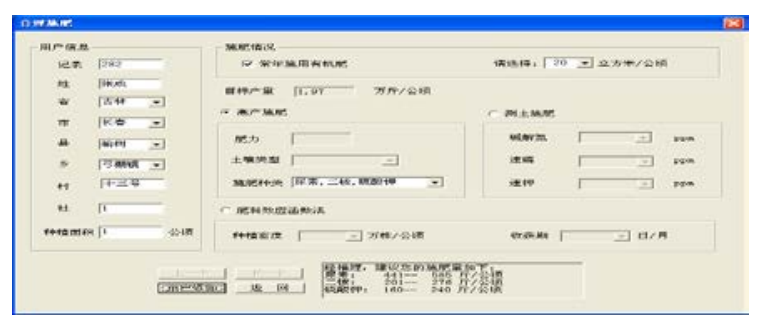

Figure 3 farmers basic information 


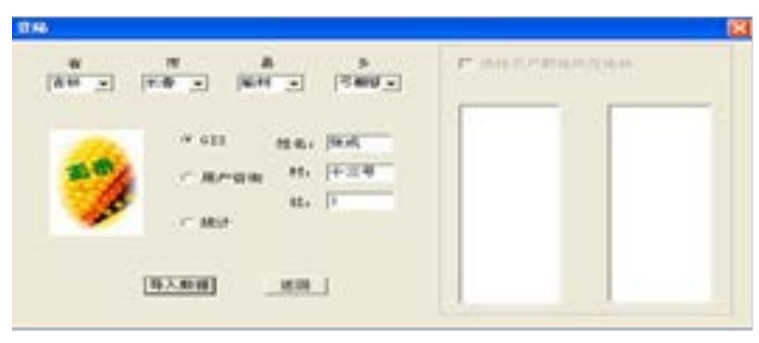

Fig.4 Register to complete

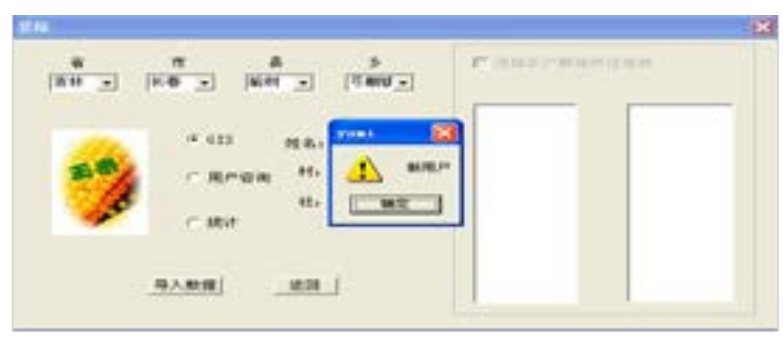

Fig5 High produce to apply fertilizer

\section{The expert system application to create benefits}

Agricultural expert system is an important part of the automation and control command system, it is an important tool to support precision agriculture. After several years of application practice, the agricultural expert system has played an important role in several aspects of the following ${ }^{[6]}$.

\section{Improve the quality of farmers}

Our country is a large agricultural country, low cultural level of the majority of farmers, poor basic scientific farming, the existing agricultural science and technology personnel can not meet the needs of the development of production and high levels of agricultural experts is the lack of agricultural production decisions with greater subjective and blindness. In the past, due to the weak foundation of agriculture technology and other reasons, related to agricultural production and the accumulation of data collection, optimization modeling, database creation and application aspects have a lot of problems, a simple simulation and optimization also has limitations. Agricultural expert system different from the general electronics Popular Science, which has analysis, reasoning, calculations, and a variety of functions, is difficult to compare electronic books. Agriculture expert system integration knowledge and experience of experts, according to the local prevailing circumstances, give a very intuitive, easy to understand and compare accurate observations ${ }^{[7]}$. It can play a high level, the role of many agricultural experts, farmers use expert systems to guide the production, simple and fast. It plays a significant role in the production, income and reduce costs, thus easily accepted by farmers and rural cadres, improve the overall quality of their scientific and cultural awareness and scientific farming.

\section{Improve the utilization of fertilizers, promoting the sustainable use of arable land resources}

Agriculture expert system integration knowledge and experience of experts groups, according to different natural conditions, economic factors, comprehensive reasoning, according to local conditions, and the time to provide the most suitable type of fertilizers to the user, the best time of fertilization, the most reasonable the fertilizer and advanced fertilization methods, and also provide fertilizer to prevent volatilization, leaching or fixing technical measures, the use of fertilizer with a scientific and rational basis, overcome blindness to improve fertilizer efficiency, reduce fertilizer costs $^{[8]}$. In addition, with the development of transport, energy and tourism industries, China's arable land is difficult to expand, we can only take the content-type soil-conservation and protection system, improve resource utilization and productivity, agricultural expert system according to the user's production conditions scientific decision-making, to provide users with crop planting patterns, soil way, reasonable indicators and specific cultivation measures to improve the efficiency and productivity of arable land, is conducive to fertilize the soil, protecting the environment, so that the limited arable land resources maximize of the utilization .

\section{Increase maize production, Increase farmers income}

Experience and knowledge of experts is extremely valuable, in some respects, the agricultural expert system can replace expert, in particular, can bring together the wisdom of expert groups, 
long-term "extended stay" in the countryside, "accompany" the peasant side, has calculated accurately reflect the speed fast, "memory" strong features, can play specialist is difficult to play the role never go experts, the majority of agricultural scientists and farmers welcome.

In recent years, the practice has proved that drinking maize production expert system software to guide maize production, improve product quality and yield of corn, reducing fertilizer inputs, increase competitiveness in the international corn market corn, maize production expert system has broad application prospects.

\section{Reference}

[1] Long teng-Fang, Guo Keting expert systems in the field of agriculture application [J] Shaoguan University (Natural Science), 2003,24 (9): 34-36

[2] Joel O.Paz, William D.Batchelor, and Palle Pedersen WebGro:.. A Web-Based Soybeen Management Decision Support System [J] AGRONOMYJOURNAL. VOL.96. NOVEMBERDECEMBER 2004,1771-1779

[3] Yao yu-xia,The Research and Application of Remote Sensing Technology in MaizeYield Estimation of Jilin, 2014IEEE Workshaop on Advanced Research and Technology Industry Applications(WARTIA) OTTAWA CANADA 2014.9(215-218)

[4] GF Chen. Corn Intelligent Digital Information Management System Based on GIS Research. Journal of Xin Jiang Agricultural Science, : Vol 36-39. (2007) p1.

[5] Yao Yu-xia,multimedia rice production of intelligent systems [J]. Journal of Jilin University, 2005 (4) 436-440

[6] Zhao Ze-ying, Peng Zhiliang, Treatment System and other corn cultivation expert system and its application in karst mountain [J] Agricultural Information Sciences, 2004,20 (6): 316-326

[7] Xie Li, Research and Explore the Application of Precision Ariculture in GongPeng Town Please. Agricultural Information Network, Vol 18-20(.2009 ) p2

[8] Cai jia-pei , Application of Computer Technology in Maize Production Implementation Precision Agriculture, Selected peer reviewed papers from the $20144^{\text {th }}$ international Conference on intelligent System and Applied Material (GSAM 2014) August 23-24,2014, Taiyuan, China. 2014.11(2153-2156) 